\title{
La verdad histórica del espiritismo
}

\section{The historical truth about spiritism}

\author{
José Carlos Loredo Narciandi \\ Profesor, Facultad de Psicología/Universidad Nacional de Educación a Distancia (Uned). \\ Madrid - Comunidad de Madrid - España \\ jcloredo@psi.uned.es
}

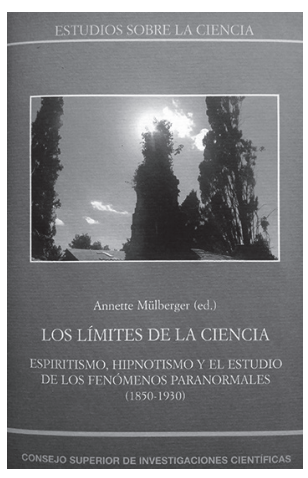

MÜLBERGER, Annette (Ed.). Los límites de la ciencia: espiritismo, hipnotismo y el estudio de los fenómenos paranormales (18501930). Madrid: Consejo Superior de Investigaciones Científicas. 2016. 346p.
$\mathrm{T}$ al y como la editora señala en la introducción, desde su nacimiento el espiritismo fue un fenómeno controvertido. Muchos lo reducían a un puro fraude ligado a la superchería. Otros se interesaban abiertamente por el tema, y no como mero objeto de estudio, sino a menudo en virtud de una curiosidad intrínseca que les llevaba a investigar si realmente los fenómenos que lo caracterizaban consistían en simples trucos. Algunos incluso consideraban la posibilidad de que fueran producidos por espíritus. En todo caso, la metapsíquica, la investigación psíquica o la parapsicología pretendían tematizar científicamente esos fenómenos. El fraude no lo explica todo, porque excluye a quienes actuaban de buena fe. El espiritismo ha sido un fenómeno sociocultural de primer orden que no debería ventilarse como un engaño colectivo o un error histórico. Según muestra este libro, a finales del siglo XIX y principios de XX, estaba mezclado con disciplinas como la psicología, la fisiología o la física. De hecho, la principal aportación del libro es estudiarlo desde el punto de vista de la historia de la ciencia.

Actualmente el espiritismo ha caído del lado de lo pseudocientífico.

Encontramos o defensores o detractores. Todos ellos se muestran poco interesados en mostrar su funcionalidad cultural, su porqué. Es evidente que los fantasmas no existen según la misma modalidad ontológica que las mesas o las piedras, pero ¿cómo funciona "realmente" el espiritismo?, ¿qué tipo de práctica es? Abordándolo como objeto de estudio historiográfico, este libro nos ayuda a responder. Pretende atenerse a la complejidad que lo envolvía hace cien años. Por eso constituye un buen ejercicio de historia de la ciencia. Un ejercicio que los autodenominados escépticos quizá tachen de equidistante dada la renuncia explícita a proporcionar "respuestas simplistas que muestren una imagen en blanco y negro de los pros y los contras" (p.17). En cierto modo, esa renuncia revela una honradez historiográfica que es la que permite abordar el espiritismo como fenómeno histórico-cultural vinculado a la ciencia moderna. Constituyó un producto original en 
el que convergieron la sociedad del espectáculo, las formas de religiosidad del Nuevo Mundo, el ilusionismo, el liberalismo, el reformismo social, el anarquismo, el socialismo, el feminismo etc., aparte de la ciencia y la tecnología de la época (el electromagnetismo, los rayos $\mathrm{X}$, la radiofonía, la fotografía...). Implicaba una cosmovisión muy afín a la científica $y$, al igual que ésta, ligada a proyectos de mejora de la sociedad. A lo largo de las páginas del libro se muestra su funcionalidad como dispositivo que reunía a hombres y mujeres (en un momento en que la mezcla de géneros era poco habitual), ofrecía una filosofía de vida liberada de las constricciones de la moral religiosa o tradicional, y fundamentaba proyectos políticos progresistas. También permitía a numerosos científicos conciliar la racionalidad científica con esperanzas terrenales y ultraterrenales.

Las fuentes primarias predominantes en los diversos capítulos son españolas, aunque gran parte de lo que se narra es generalizable. Tras un prólogo de Antoni Roca y la introducción de la editora, la propia Annette Mülberger dedica los tres primeros capítulos a contar cómo fue el origen del espiritismo, cómo se implantó en España y cómo los fenómenos paranormales se estudiaban buscando alianzas con las ciencias de la época y haciendo gala de una actitud acusadamente empírica. A la postre, tal actitud buscaba aplicar lo que hoy muchos siguen llamando acríticamente "método científico". Cuando los fenómenos se daban por auténticos, las explicaciones eran diversas. Por ejemplo, se basaban en efectos electromagnéticos o en procesos psíquicos inconscientes, patológicos según algunos y creativos según otros.

El capítulo cuarto, de Andrea Graus, resume el tratamiento de la mediumnidad en España durante el periodo estudiado. El quinto capítulo, firmado por Ángel González, hace lo propio con el hipnotismo y muestra las estrategias utilizadas por sus practicantes para lograr su aceptación dentro, sobre todo, del ámbito de la medicina. Vemos que un hilo conductor principal del volumen es el que revela las conexiones entre el mundo de lo paranormal y el de lo científico. Como dije hace un momento, la metapsíquica aspiraba a estrechar esas conexiones. A ello se dedica, mediante el estudio de un caso, el capítulo sexto, de Mònica Balltondre. El caso es el del marqués de Santa Cara, estudioso de la telepatía y la clarividencia. La última parte del libro, donde he echado de menos la referencia de Guillaume Cuchet (2012), Les voix d'outre-tombe, va allende los Pirineos dedicando el capítulo séptimo, de Nicole Edelman, a los casos de videncia en la Europa occidental durante el primer tercio del siglo pasado. El octavo capítulo, de Michael D. Gordin, está dedicado a analizar la comisión para el estudio de los fenómenos espiritistas creada en San Petersburgo en 1875 de la que formaban parte celebridades como el químico Dmitri Mendeléyev. Un interesante epílogo de la editora cierra el libro apuntando hacia el presente.

Una de las posibles moralejas de esta obra es la que considerase el espiritismo decimonónico como una posibilidad que, si bien acabó cayendo del lado de lo pseudocientífico, podría haber evolucionado en una dirección más "respetable" hibridándose acaso con algunas tendencias de la psicología u otras disciplinas. Pero es preciso evitar la tentación de la historia ficción. Ahora bien, probablemente no sea del todo cierto que el historiador haya de ser neutral y deba por tanto analizar el espiritismo al margen de si sus doctrinas eran o no verdaderas. El análisis historiográfico podría incluir perfectamente una reconstrucción de la "verdad" del espiritismo. No en sus propios 
términos, sino en otros. Al margen de las teorías espiritistas, ¿qué significó la práctica del espiritismo? ¿Por qué la gente decía - y dice - ver cómo se mueve una pieza de madera o un vaso invertido respondiendo a preguntas que solo un participante en la séance conoce? Al margen del engaño puro y duro, cabe apelar a fenómenos de sugestión, un concepto por lo demás muy de la época. Sin embargo, lo interesante es el funcionamiento concreto de las sesiones de espiritismo, que es lo que permite la construcción, como producto de la propia ceremonia, de la experiencia de la que informan los participantes. Tal vez una vía prometedora sea analizarlo como un dispositivo de subjetivación, esto es, un conjunto de prácticas sistematizadas e institucionalizadas que producen determinadas experiencias, lo mismo que hacen la psicoterapia y otras formas de curación o transformación personal. No es algo inédito. Hay algunos trabajos en los que apoyarse. El artículo de García Álvarez, Cabanas Díaz y Loredo Narciandi (2015), "La cura mental de Phineas P. Quimby y el origen de la psicoterapia moderna" esboza algunas continuidades entre una práctica de curación, digamos silvestre, que estuvo de moda en la Norteamérica del siglo XIX, y la psicología clínica moderna. De una manera más específica y con material empírico de carácter etnográfico, un artículo de Daiana Baroni y Arthur Ferreira (2016) se titula precisamente (traduzco del portugués) "Tratamientos espirituales mediúmnicos y producción de subjetividad". Por último, el libro de Vinciane Despret (2015), Au bonheur des morts, también da alguna pista interesante incidiendo en la funcionalidad del modo de existencia de los muertos dentro de la existencia de los vivos.

Más allá del contenido doctrinal del espiritismo, la verdadera "explicación" de éste probablemente venga dada por la convergencia de aproximaciones historiográficas como las del libro editado por Annette Mülberger y aproximaciones teóricas o antropológicas basadas en su carácter de práctica de subjetivación. Cuando menos, la historia nos enseña que las cosas no han sido nada simples y las disciplinas con aspiración científica han cultivado la promiscuidad.

\section{REFERENCIAS}

BARONI, Daiana Paula Milani; FERREIRA, Arthur Arruda Leal.

Tratamentos espirituais mediúnicos e produção de subjetividade. Mnemosine, v.12, n.1, p.30-44. 2016.

CUCHET, Guillaume.

Les voix d'outre-tombe: tables tournantes, spiritisme et société au XIXe siècle. Paris: Éditions du Seuil. 2012.

DESPRET, Vinciane.

Au bonheur des morts: récits de ceux qui restent. Paris: Les Empêcheurs de Penser en Rond; La Découverte. 2015.
GARCÍA ÁLVAREZ, Roberto; CABANAS DÍAZ, Edgar; LOREDO NARCIANDI, José Carlos. La cura mental de Phineas P. Quimby y el origen de la psicoterapia moderna. Revista de Historia de la Psicología, v.36, n.1, p.135-154. 2015.

MÜLBERGER, Annette (Ed.).

Los límites de la ciencia: espiritismo, hipnotismo y el estudio de los fenómenos paranormales (1850-1930). Madrid: Consejo Superior de Investigaciones Científicas. 2016. 